\title{
LNG dispersion over the sea
}

\author{
A. Fatsis ${ }^{1}$, J. Statharas ${ }^{2}$, A. Panoutsopoulou ${ }^{3} \&$ N. Vlachakis ${ }^{1}$ \\ ${ }^{1}$ Technological University of Chalkis, \\ Department of Mechanical Engineering, Psachna Evias, Greece \\ ${ }^{2}$ Technological University of Chalkis, \\ Department of Aeronautical Engineering, Psachna Evias, Greece \\ ${ }^{3}$ Hellenic Defence Systems, Athens, Greece
}

\begin{abstract}
A numerical study of heavy gas dispersion over sea from an LNG storage facility at Renythousa Island in Greece is examined for the various hazards imposed on the population of the surrounding areas. The study is done by using the code ADREA-HF solving the conservation equations of mass, momentum and energy for the mixture of the heavy gas and air, as well as the mass fraction of heavy gas. Distributions of methane, ethane and propane concentrations for various time instants after the gas release are obtained, identifying the riskiest zones using scenarios based on weather forecast data. Thus the contribution of this work is to show how the available time for the authorities to safely evacuate the nearest affected areas can be evaluated.
\end{abstract}

Keywords: heavy gas dispersion, Navier-Stokes equations, turbulence model, flammable plume zone.

\section{Introduction}

Large quantities of substances that are hazardous for the public and for the environment are produced or utilized in large quantities by most modern process industries that are often sited near populated areas. These substances being toxic, radioactive, flammable or explosive during an accident in the production process, transportation or storage may provoke a release of gas (or gas-liquid) clouds or plumes that are denser than air. The density difference of the formulated "heavy gas" introduces buoyant forces that can distort significantly 
the local wind pattern (Deaves [1]) and the other important atmospheric transport parameters such as the atmospheric stability and the turbulent structure and level.

The reason for studying dense gas dispersion is to analyze the hazards associated with the release as a function of space and time under specific conditions and accident scenarios, in order to predict how such hazardous material is dispersed, under the specific topographic and atmospheric conditions for the safety aspects of plant design and position, as well as for contingency plans for people in danger.

The ADREA-HF code was chosen to study the accident scenario at Revythousa Island in this manuscript due to its ability to describes best the effects of obstacles in dispersion of a dense gas (been successfully used in dispersion studies such as Liquid Ammonia Dispersion) as well as the practical aspect of the free access obtained by the "National Center Scientific Research" (NCSR) DEMOCRITOS Institute of Nuclear Technology and Radiation Protection in Greece.

\section{Numerical modelling}

The ADREA - HF code has been developed to calculate the dispersion of heavier than air gases on ground of irregular complexity. It assumes a mixture of two components: the heavier than air gas and the ambient air. The code solves the conservation equations of mass, momentum and energy for mixtures and the mass fraction of heavy gas. Furthermore the code includes a heat conduction equation for a thin layer of ground $(20-50 \mathrm{~cm})$. The following equations are solved for a particular geometry of region using a finite volume methodology. For closing the system of equations the ADREA-HF code uses turbulence closure scheme. In the calculation of this project one equation turbulence model has been used, because it was found that it best describes the effects of obstacles in dispersion of a dense gas.

In the code ADREA-HF, zero- equation, one- equation and two- equation turbulence models are available. The mathematical description of ADREA -HF model has been presented by Bartzis et al. [2].

The eddy viscosity is calculated as follows:

$$
K_{i}^{m}=\left\{\begin{array}{c}
C_{\mu} \cdot k^{1 / 2} \cdot l_{\imath} \text { for } \mathrm{k}>0 \\
K_{\infty} \text { for } \mathrm{k}=0
\end{array}\right.
$$

where $\mathrm{k}$ is the turbulent kinetic energy, $l_{i}(i=x, y, z)$ is an effective length scale, $K_{\infty}=0,5 \mathrm{~m}^{2} / \mathrm{sec}$ and $C_{\mu}=0,1887$ is an empirical constant.

For the space discretization of the equations, the finite volume technique by Patankar [3] was used in the ADREA-HF code. The computation domain is divided into a number of non-overlapping finite control volumes over which the differential conservation equations are integrated. The integral equations obtained can be expressed as a sum of four parts: the accumulation, the convection, the diffusion and the generation part. 
For the time derivative in the accumulation term, a first order backward difference (implicit) scheme is applied. In the convection term, the "upwind difference" scheme is adopted. For the diffusion term, use of the "central differencing" is made. A pressure discretized equation is formed from the integrated mass conservation equation. A pressure Poisson equation is formed, utilizing the discretization equations for the velocity components.

\section{The LNG Terminal at Revythousa Island}

Revythousa. Island was chosen in 1988 to become the LNG receiving terminal from Algeria. This is located at the southern end of the natural gas system and about $30 \mathrm{~km}$ west of Athens, the main gas consumption center, figure 1 . The islet, which is 500 meters from the nearest point on the mainland, is 600 meters in length, 250 meters in breadth, rising from the sea surface level to a height of 48 meters.

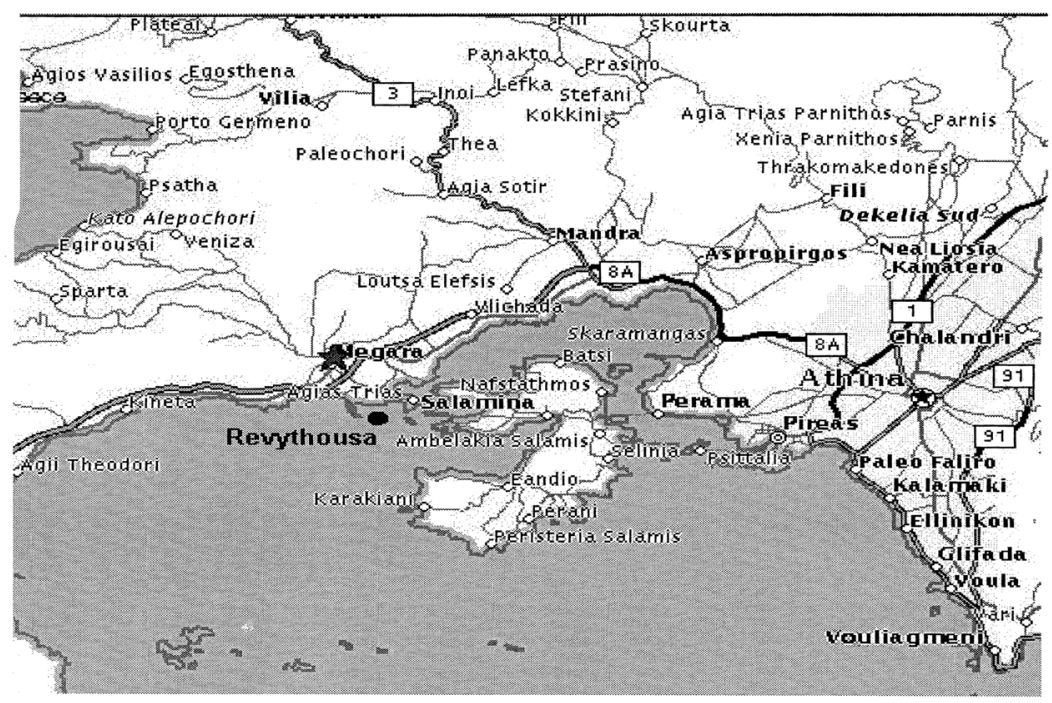

Figure 1: $\quad$ Illustration of the region in which Revythousa island is located.

The terminal is designed for normal operation as well as peak send out for gas in the network as needed, from minimum send out to emergency peak send out of $830 \mathrm{~m}^{3} / \mathrm{h}$ equivalent liquid LNG volume. Send out gas to the grid is in the range from 31 to 62 barg. Two identical full containment LNG storage tanks of total useful capacity $130000 \mathrm{~m}^{3}$ have been constructed. The tanks have top connections only and internal piping for top and bottom loading. The operation of the terminal allows the ship unloading to one storage tank, while the other tank is on grid supply service (DEPA [4]). 


\section{Accident scenario - Computational domain - Topography}

On the present release scenario considered, a great quantity of LNG leaks from a sudden break in the flank surface of a full cylindrical tank. The thermodynamic variations of $\mathrm{LNG}$ from storage conditions to ambient conditions can be considered as isentropic since these variations are very fast. The main quantity of Natural gas leaks in the ambient atmosphere at liquid phase.

It is assumed that the cylindrical tank is full and the whole quantity of LNG leaks to ambient air within $45 \mathrm{~min}$ through a parallelogram break. The average leakage mass of two phase mixture was calculated and was equal to $10709 \mathrm{~kg} / \mathrm{s}$. The exit temperature of the two phase mixture is assumed to be at the boiling point of Methane which is $-160^{\circ} \mathrm{C}$.

The three-dimensional domain consists of a parallelepiped which its twodimensional projection is shown at figure 2 (dashed parallelogram).

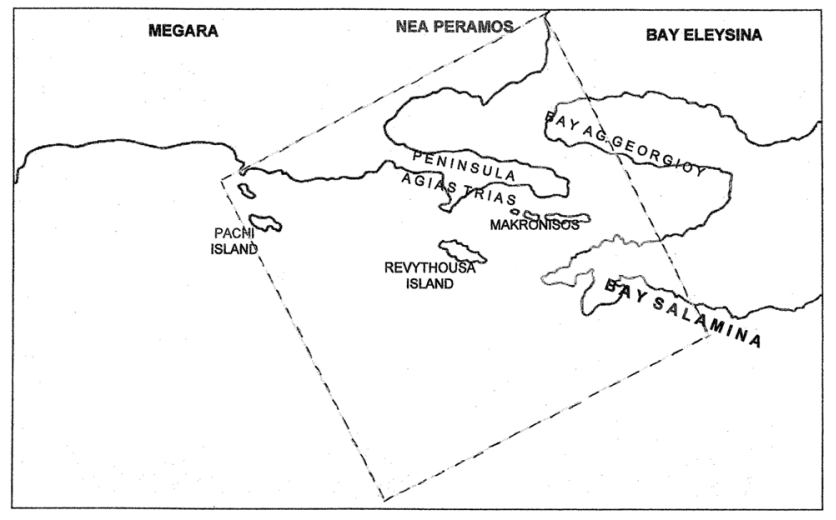

Figure 2: The Geographic region chosen as the calculation domain.

The dimensions of parallelepiped are the following: $\mathrm{X}$-axis: $10 \mathrm{~km}, \mathrm{Y}$-axis: $10 \mathrm{~km}, \mathrm{Z}$ - axis: $1 \mathrm{~km}$. The calculation domain is divided to series of smaller cells (right parallelepipeds) through out the complex 55(X-axis) 27 (Y-axis) 31(Z-axis) amounting 46035 cells. The three-dimensional grid is not uniform; it is more condense close to leakage source, which is located at the cell with coordinates $\mathrm{i}=28, \mathrm{j}=1$, and $\mathrm{k}=2$, and close to land. The smallest cell has length $40 \mathrm{~m}$ at $\mathrm{X}, \mathrm{Y}$ directions and $2 \mathrm{~m}$ at $\mathrm{Z}$ direction. The computational calculations of the ADREA HF code take in to consideration a thin layer of land. Geographic Military Service of Greece kindly provided the topography - input data at digital form.

\section{The computational steps}

In ADREA - HF, the complete simulation of the transient scenario consists of the following three stages:

- Calculation of the 1-D velocity profile 
- Calculation of the 3-D steady state wind field

- Calculation of the 3-D cloud dispersion

In case of an unchanged wind field, only the last stage had to be repeated for the simulation of a new scenario.

\subsection{Calculation of 1-D velocity profile}

The velocity on the top plane was set to a specified input value in order to obtain a desired value at $10 \mathrm{~m}$ height. The ground temperature was set to $11^{\circ} \mathrm{C}$. Vertical temperature profile was assumed to correspond to neutral stability conditions i.e.,

$$
\frac{d T}{d z}=-\frac{g}{C_{P}}
$$

where $\mathrm{g}$ is the gravitational acceleration and $C_{P}$ is the heat capacity (constant pressure).

\subsection{Boundary conditions}

The three-dimensional steady state wind field over the given geometry was calculated by solving the three momentum equations, the turbulent kinetic energy equation and the pressure equation.

For initialization the one-dimensional profiles calculated previously were applied at the three dimensional domain. The boundary conditions were specified as follows according to Statharas et al. [5]:

- $\quad$ On the ground the calculated parameters are assumed to have a specified value, except for temperature where a zero gradient was assumed.

- $\quad$ On the source surface a value plus a zero gradient was specified for all the parameters

- $\quad$ For the input domain plane, the boundary conditions are the same with the ones at the source surface, except for the vertical velocity component where a value was specified.

- $\quad$ For the other domain planes, it is assumed that the parameters have a zero gradient except for the vertical velocity component, which is specified in a value.

\section{Results and discussion}

The upper and lower flammability limits are particular for each component of Liquid Natural Gas. The riskiest zone takes place between lower and upper flammability limits. The worst instant time is, when the riskiest zone covers the greatest field of overland. Figure $3 \mathrm{~b}$ shows the riskiest zone of methane at sea level at time $\mathrm{t}=500 \mathrm{~s}$ after the accident.

The methane concentration at sea level, at $t=400 \mathrm{~s}$ is indicated by Figure $3 \mathrm{a}$ that with D2 wind condition and wind direction towards Megera town, the riskiest zone covers section of overland field as Peninsula Agias Trias, Bay 
Salamina, and Makronisos Island. Furthermore, the width of flammable zone is significant at this instant time because of the dispersion of Methane dense cloud to atmosphere, which just begins.

The methane concentration at sea level, at $t=500 \mathrm{~s}$ is indicated by figure $3 \mathrm{~b}$ that with D2 wind condition and wind direction towards Megera town, the flammable zone continues to cover section of overland field as Peninsula Agias Trias, Bay Salamina, and Makronisos Island. According to the above graph, it can be seen that the flammable cloud field has slightly reduced due to continuative dilution by ambient air. Furthermore, it should be pointed out that the form and the extent of upper flammable limit are decreased and differ from the figure $3 \mathrm{a}$.

The methane concentration at sea level at $\mathrm{t}=1000 \mathrm{~s}$ is significantly different with respect to previous situations. It is noted that with D2 wind condition and wind direction towards Megera town, the riskiest zone continues to cover section of overland region as Peninsula Agias Trias, Bay Salamina, and Makronisos Island. It is worth noting that the figure $3 \mathrm{c}$ shows the ring of flammable cloud significantly narrowed, while the upper flammability limit has been extended. This means that the lower flammability limit field is reduced and the upper flammability limit is increased. Consequently the flammable ring is being narrowed.
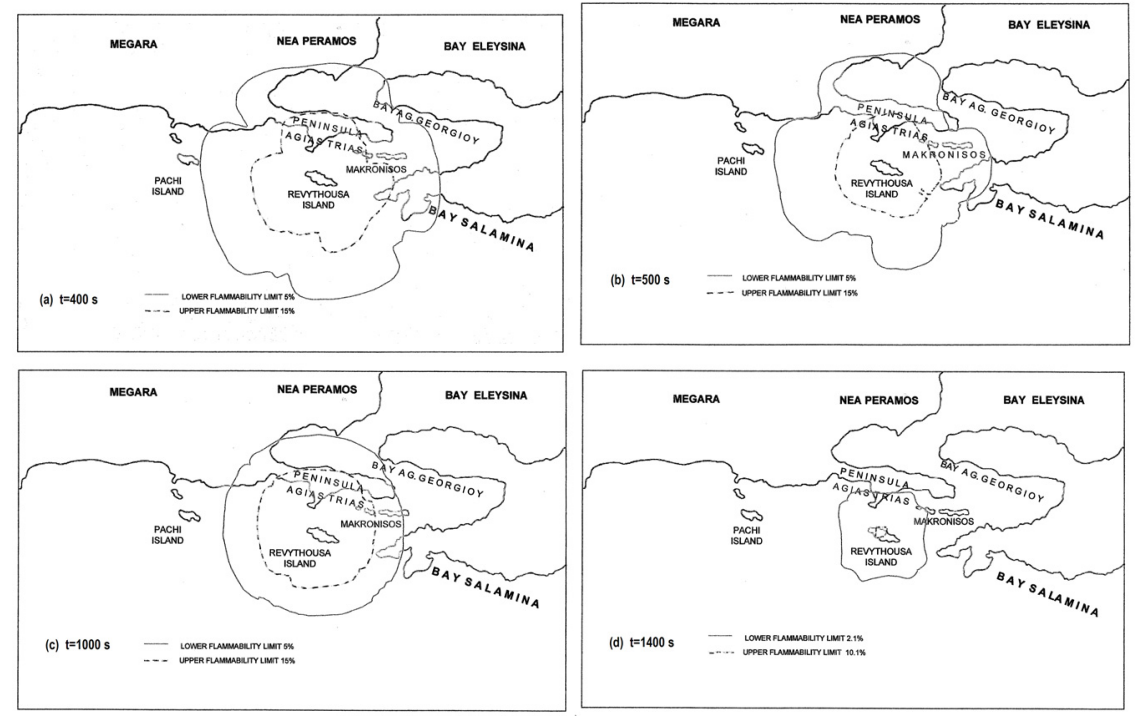

Figure 3: The methane distribution at different time instants after the release.

The shape of Methane dense cloud as it is illustrated at figure $3 \mathrm{~d}$ of $\mathrm{t}=1400 \mathrm{~s}$ is similar to that of $t=1000 \mathrm{~s}$. It has a slight difference of upper flammability limit field, which is noted slightly reduced, but the flammable cloud continues to cover section of overland region as Peninsula Agias Trias, Bay Salamina, and 
Makronisos Island. A 2-D view of the leakage plume at various time instants is shown in Figure 4.
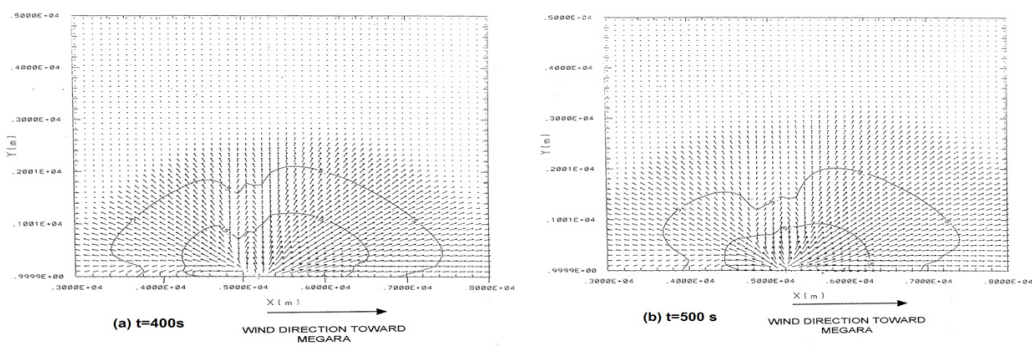

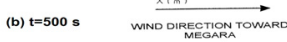
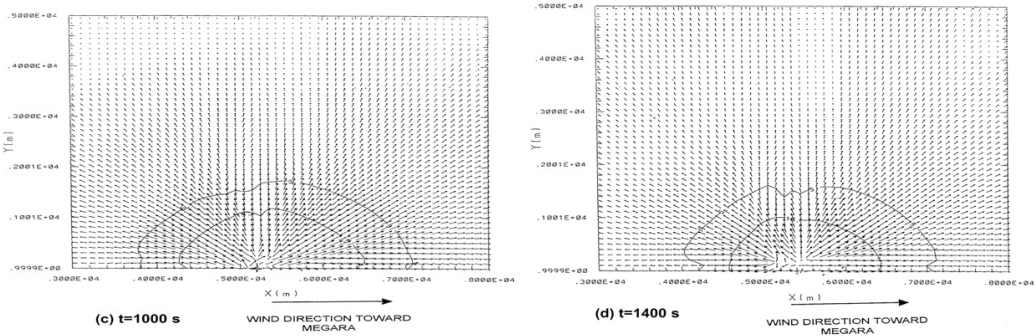

Figure 4: $2-\mathrm{D}$ view of the methane leakage plume at various time instants.
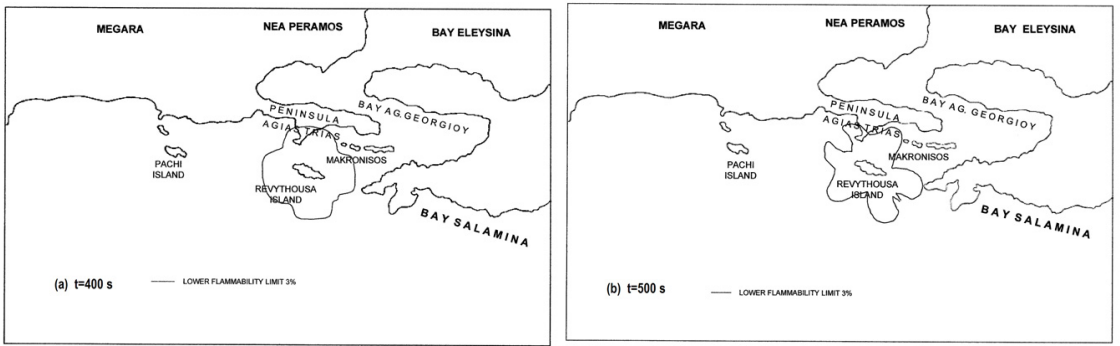

Figure 5: The ethane distribution at different time instants after the release.

The plume formed for ethane at sea level at $\mathrm{t}=400 \mathrm{~s}$ with wind conditions D2 and with direction towards Megara town cover a section of overland region as Peninsula Agias Trias and Revythousa Island. Figure 5a has shown that the flammable cloud is in the form of umbrella and not in the formed ring. This happens because during the time, ethane has not reached at the upper flammability limits. The flammable cloud has not been diluted enough and the magnitude of flammable cloud field has not been stabilized yet.

Figure 6 shows a 2-D view of the leakage plume of ethane at various time instants.

The propane concentration at sea level and for instant time $\mathrm{t}=400 \mathrm{~s}$, it is noted that with wind condition D2 and wind direction towards Megara, the riskiest flammable zone for propane covers a section of overland region such as 
Peninsula Agias Trias, a part of Revythousa Island and a part of Makronisos Island. Figure $8 \mathrm{a}$ appears that the form of flammable zone is a very width ring. Also, it can be seen that the upper flammability limit is only limited on Revythousa island.
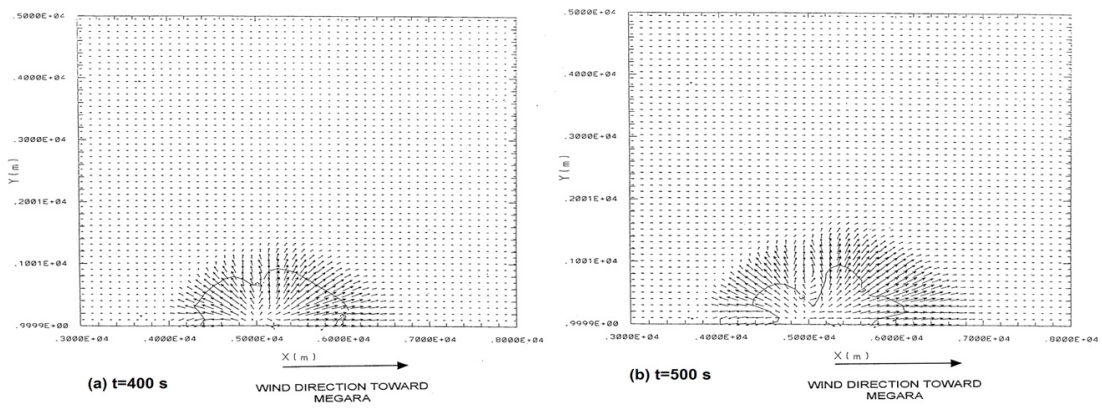

Figure 6: 2-D view of the methane leakage plume at various time instants.

The propane concentration at sea level and for instant time $\mathrm{t}=500 \mathrm{~s}$, it is noted that with wind condition D2 and wind direction towards Megara, the flammable cloud continues to cover a section of overland region such as Peninsula Agias Trias, a part of Revythousa Island and a part of Makronisos Island. Figure 7b illustrates that the flammable field zone has been slightly increased due to continuative dilution by ambient air. While the shape and the extent of upper flammable limit are slightly different from the previous situation.
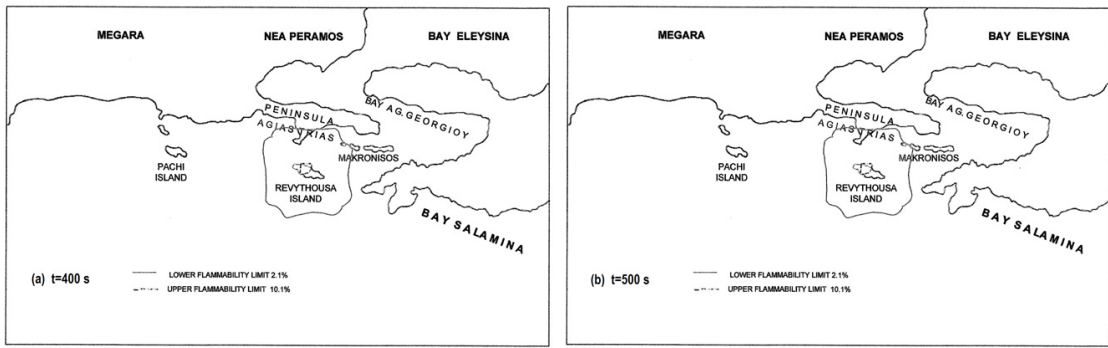

Figure 7: The propane distribution at different time instants after the release.

A 2-D view of the propane leakage plume at various time instants is shown in figure 8 .

\section{Conclusions}

According to the above graphs, it can be seen that Megara region, which is the most populated at the surround area, is not in danger for a period of one hour and ten minutes, from the beginning of the leakage. It means that 45 minutes for 

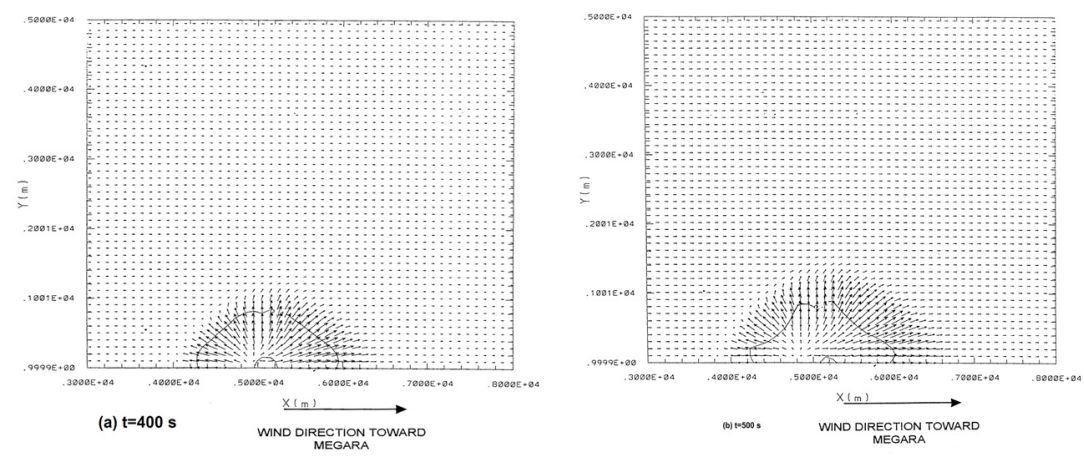

Figure 8: $\quad 2-\mathrm{D}$ view of the propane leakage plume at various time instants.

complete discharge of the tank and 25 minutes approximately of modeling calculations, Megara town is out of risky zone. This is offered due to location of LNG terminal at Revythousa Island subsequently the flammable cloud covers mainly a section of overseas region.

However the regions such as Peninsula Agias Trias, Revythousa Island, Makronisos Island, Bay Salamina, are directly in danger due to flammable cloud of Methane, Ethane, Propane during one hour and ten minutes, in which is moved with coherence and not separately. This means that the cloud remains flammable out of flammable limits of each component.

Particularly the maximum risk occurs at time $\mathrm{t}=400 \mathrm{~s}$ for all three components. At this time the maximum range in which each component reaches is: $2000 \mathrm{~m}$ for Methane, $1000 \mathrm{~m}$ for Ethane, and $800 \mathrm{~m}$ for Propane.

\section{References}

[1] Deaves D.M., Application of a turbulence flow model to heavy gas dispersion in complex situations, Heavy Gas and Risk Assessment-II, ed. Hartwing S, D. Reidel Publication Co., 1983.

[2] Bartzis J.G., Venetsanos A.G., Varvayanni M, Catsaros N. \& Megaritou A., ADREA-I: A Transient Three-Dimensional Transport Code for Complex Terrain and Other Applications, Nuclear Technology, 94, 1991, pp. 135148.

[3] Patankar S.V., Numerical Heat Transfer and Fluid Flow, New York, Hemisphere Publishing Co, 1980.

[4] Public Gas Corporation of Greece S.A. (DEPA), Plans for Natural Gas importation into Greece: The LNG terminal at Revythousa Island, 1997.

[5] Statharas J.C., Bartzis J.C., Venetsanos A. \& Wurtz J., Prediction of Ammonia Releases using ADREA-HF Code, Process Safety Progress, 12, 1993, pp. 118-122. 